\title{
PROJETO CASA AMARELA: UMA EXPERIÊNCIA DE INCLUSÃO
}

Mára Beatriz Pucci de Mattos ${ }^{1}$

\section{RESUMO}

Este artigo tem como objetivo relatar a experiência do Projeto de Extensão Casa Amarela - INTERARTE IFRN/CAPS, enquanto processo educativo, artísticocultural de inclusão de pessoas com transtorno mental e dependência, desenvolvido no Campus Natal - Cidade Alta, do IFRN. O projeto é metáfora do sonho do artista Van Gogh e se consolida nas práticas colaborativas de uma equipe multidisciplinar, integrada por docentes, psicóloga, alunos e estagiários do curso de Produção Cultural e dos Centros de Atenção Psicossocial, compromissados com acesso à educação e ao direito cultural. $\mathrm{O}$ artigo dividese em introdução, desenvolvimento e considerações finais, utilizando-se da metodologia do DBAE, portfólio e voluntariado para oferta de curso em pintura, desenho, dança e papel reciclado. A relação entre o IFRN e a sociedade instaura um processo terapêutico, que ressignifica estigmas históricos e ameniza o sofrimento emocional para reinserção social de pessoas, para o gozo do direito cultural e do exercício pleno da cidadania.

Palavras-chave: Inclusão. Arte. Equipe multidisciplinar.

\section{INTRODUÇÃO}

O quadro "A Casa Amarela", óleo sobre tela, pintado em setembro de 1888 pelo artista holandês Vincent Van Gogh, retrata o sonho de formar uma confraria de artistas em permanente diálogo com a arte. O prédio do Campus Natal Cidade Alta, do IFRN, restaurado em 2009, na sua cor e nos seus ideais, guarda similaridade com o sonho de vida de Vincent Van Gogh: constituir um centro cultural e educativo e manter uma equipe multidisciplinar, comprometida com a formação humana, na perspectiva da "arte para todos".

A história da arte evidencia o descaso frente à doença mental e à sua consequente exclusão presente na vida de Van Gogh e de Arthur Bispo do Rosário. Criado em 2011 pela coordenadora e professora Mára Beatriz Pucci de Mattos, o Projeto de Extensão Casa Amarela incorporou dois cursos na área de pintura e desenho de histórias em quadrinhos, culminando com uma exposição da produção artística dos alunos na Galeria de Arte.

Em 2012 e 2013, o Projeto Casa Amarela trabalhou a autonomia dos sujeitos e a produção artística, promovendo a convivência com pessoas com transtorno mental, surdos e moradores de rua, qualificando o trato docente com a diversidade. No ano de 2013, a parceria do IFRN com o Centro de Atenção Psicossocial Infanto Juvenil (CAPS)- Natal, criou um espaço de 
reinserção de, aproximadamente, 15 pessoas com deficiência, perfazendo um total de mais de 200 alunos da comunidade envolvidos no projeto e em eventos artístico-culturais, que responderam bem à inclusão. Participaram da concepção do Projeto de Extensão Casa Amarela INTERARTE IFRN/CAPS as professoras Mára Beatriz Pucci de Mattos (IFRN), Maria das Graças Pinheiro Abrantes (CAPS) e a psicóloga Maria da Conceição Araújo Valença (CAPS).

$\mathrm{O}$ agir inclusivo mobilizou um contingente de profissionais para ofertar, em 2014, quatro cursos de desenho, pintura, dança e reciclagem de papel, forjando a brecha da exclusão para reinserção social e sustentabilidade. Na sua $3^{a}$ fase, o projeto envolveu o IFRN e a Secretaria Municipal de Saúde, por meio dos Centros de Atenção Psicossocial de Natal, no compromisso educativo com a qualidade de vida de pessoas com transtorno mental. Novas metodologias da arte permitem aos aprendizes construir conhecimentos, habilidades e competências para expressão criativa e profissionalização. O encerramento anual do projeto culmina com uma exposição coletiva, na Galeria de Arte, que possibilita a inserção dos alunos no mercado das profissões e da arte.

O Projeto Casa Amarela tem como intuito fomentar parceria entre IFRN, secretarias municipais, CAPS e comunidade, de modo a incluir pessoas, com ou sem dependência ou deficiências, nos cursos de extensão do Campus Natal - Cidade Alta do IFRN. Além disso, o presente projeto assegura o convívio com a diversidade, bem como o acesso ao direito cultural e à educação pública gratuita para o exercício da cidadania, desenvolvendo também uma cultura de reciclagem e o esforço para reintegrar pessoas da comunidade no processo de escolarização.

Este artigo apresenta-se dividido em introdução, desenvolvimento, considerações finais e referências. O voluntariado, o portfólio e a Discipline-Based Art Education apresentam-se como opções metodológicas para incubar novas aprendizagens e incentivar a reinserção de pessoas com deficiências ou dependências distintas no mercado das profissões, condicionado ao potencial criativo dos indivíduos. Van Gogh pressentia um renascimento pela arte: "[...] tenho a impressão de que nós mesmos não servimos mais do que como intermediários. E que somente a nova geração poderá viver em paz. Sem levar isso em conta, nossos deveres e as possibilidades de ação se tornarão mais claras somente através de nossa experiência" (BONGER, 2008, p. 291).

\section{DESENVOLVIMENTO}

Laços culturais e afinidades com base em memórias comuns constituem elos entre membros de associações e comunidades globais. Constituídos como indivíduos, segundo Iván Izquierdo (2011), os seres humanos têm necessidade de agrupamentos, sendo essa interação mais intensa em membros de confrarias mais evoluídas.

Na Constituição de 1988 (BRASIL, 1988), o direito cultural, como bem jurídico, equiparou o termo patrimônio público à cultura, arte e história do povo brasileiro; determinou a competência da União, Estados, Distrito Federal e dos Municípios para proporcionar os meios de acesso à cultura. $\mathrm{O}$ texto constitucional de 1988 consagrou os valores vetores da sociedade brasileira e os direitos disciplinados e respeitados.

O desafio atual aos educadores reside no reconhecimento e na efetiva adoção de políticas, meios e ações, para que os direitos culturais sejam respeitados e forjados no exercício do poder por um conjunto de pessoas que, segundo Wallerstein (1997), integram a realidade social, universal ou particular, enquanto arena de batalhas sociais.

No Projeto Casa Amarela, três metodologias estão em harmonia: metodologia de desenvolvimento básico da arte educação; metodologia do portfólio; metodologia do voluntariado. Na primeira, a contextualização histórico-social, a estética e a apreciação crítica fundamentam a criação artística; na segunda, o portfólio registra e armazena dados de observações, análises críticas e produções artísticas de cada aluno, evidenciando nível de qualidade de seus itinerários formativos; na terceira, o voluntariado celebra as trocas e permuta a docência com a discência, desafiando o professor a abrir espaço para que os alunos exercitem habilidades e saberes adquiridos durante a escolarização e a vida, cooperando com o conhecimento dos colegas e evitando o individualismo.

A alternância de papéis leva à exclusão do medo de se expor e apresentar suas ideias e convicções, valorizando conhecimentos da família, escola, sociedade e cultura, com vistas ao desenvolvimento dual do cérebro - segundo Edwards (2003), habilidade global -, o diálogo e a prática crítico-reflexiva para criar inteligência plena. 


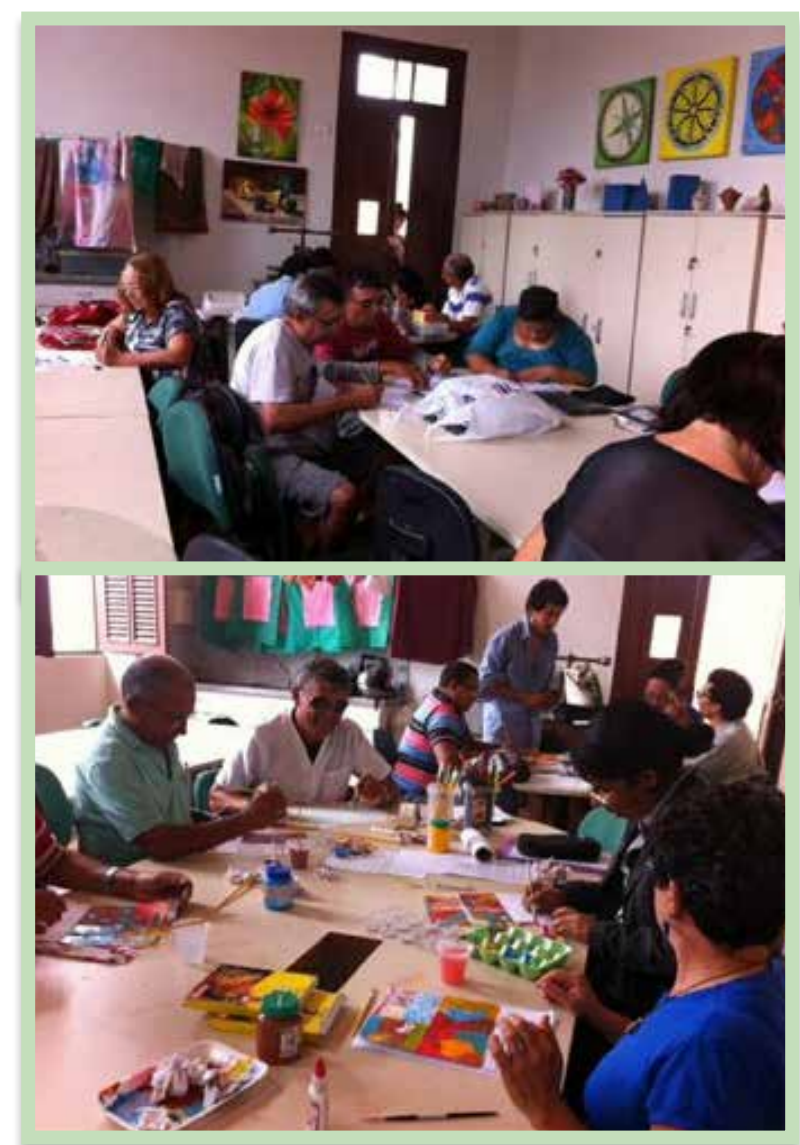

Figura 1: Alunos em atividades no projeto

A arte torna-se ferramenta terapêutica para dirimir dilemas causados pela exclusão e cria uma dinâmica de fruição e participação nos eventos e ações educativas, articulando ensino, pesquisa e extensão, base da relação transformadora entre o IFRN e a sociedade.

O compartilhamento cria laços de confiança, apoio mútuo, segundo Young (2007), e infraestrutura sobreposta à hierarquia funcional, determinando o grau de sucesso alcançado no projeto. A equipe multidisciplinar tornou-se meio/instrumento de apropriação afetiva do Campus Natal Cidade Alta, por agregar professoras e alunos do IFRN, docentes, psicóloga e estagiários do CAPS, que participam das atividades do projeto. A arte no "velho casarão", da antiga Escola de Ofícios, por sua vez, torna-se uma referência de aprendizagem e de inclusão social.

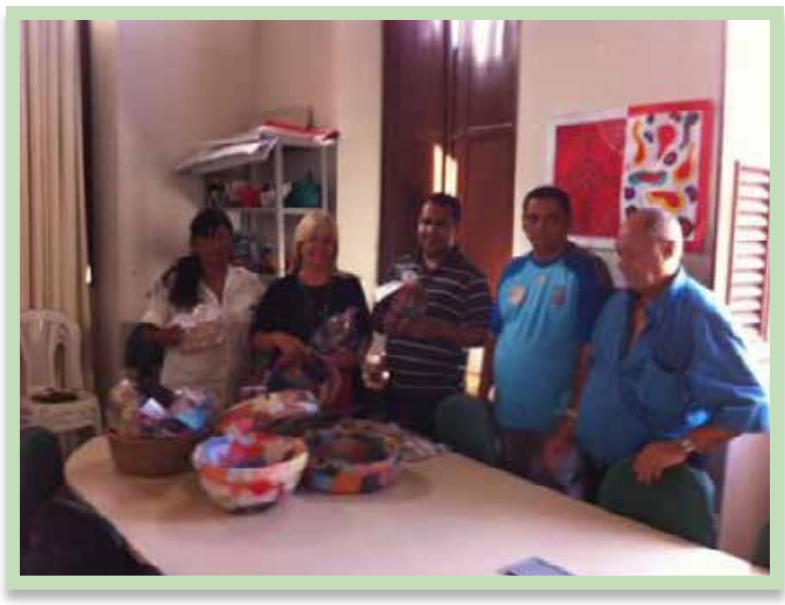

Figura 2: Materiais produzidos por alunos do projeto

Nos empreendimentos do Projeto Casa Amarela, a avaliação é feita a partir da frequência do aluno, da qualidade e da quantidade de trabalhos e da participação na exposição na Galeria de Arte. Para Paulo Freire (2011), o aprendizado associa-se à tomada de consciência da situação real vivida pelo educando e ao diálogo como condição para inovar os modos pedagógicos e a prdução da inteligência coletiva.

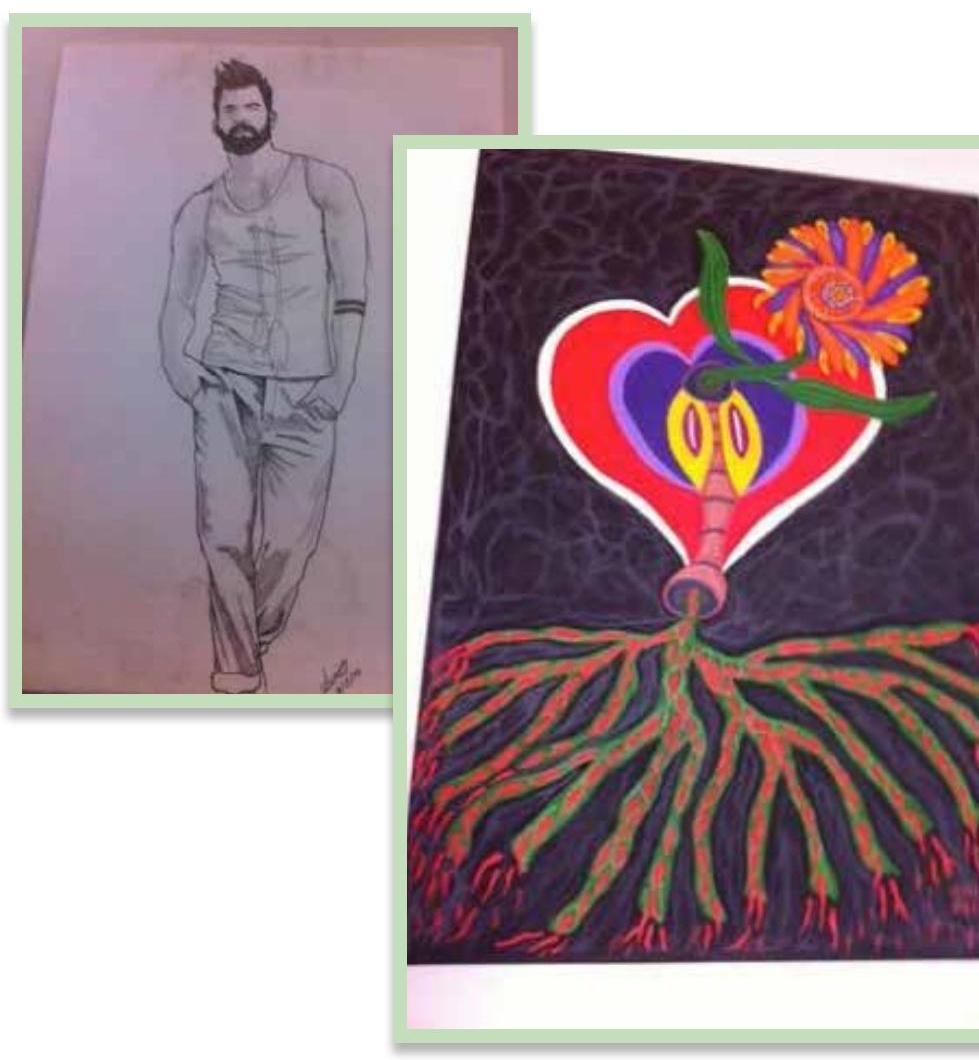

Figura 3: Obras produzidas por participantes do projeto 


\section{CONSIDERAÇÕES FINAIS}

O projeto Casa Amarela, como espaço de diálogo e compartilhamento de poder, revisa as formas de relacionamento da instituição IFRN com segmentos populares estigmatizados pela deficiência e pela dependência. A partir do momento em que a sociedade se apropria dos espaços do Campus Natal - Cidade Alta, vislumbra-se o exercício da cidadania.

As experiências formativas de extensão gratuitas, na área de artes, já incluíram mais de três centenas de pessoas da comunidade de Natal. A parceria com os Centros de Atenção Psicossocial evidencia melhoria da qualidade de vida para a coletividade e maior entendimento dos propósitos da arte, pois, segundo Jimenez (1999), enseja autonomia e o desafio de reconciliar as provocações individuais com a prática coletiva.

O Campus Natal - Cidade Alta ostentou uma reforma, a qual trouxe à edificação novos sentidos e significados. Ao refletir sobre condicionantes e elitismos históricos de acesso à arte, repensa-se a ação do poder público e os entraves que ainda persistem para garantir o direito à educação e à cultura à comunidade. Nesse sentido, o Projeto Casa Amarela intervém, de forma orgânica e colaborativa, para que professores e alunos do IFRN, profissionais e usuários do CAPS, de modo conjunto e compromissado, compartilhem o que de melhor cada um tem. Esse processo de emancipação nasce da relação do homem com sua cultura para estruturação da consciência crítica e ação comunitária, porque, segundo UNESCO (1994), a reforma das instituições sociais depende da conviç̧ão, empenho e boa vontade dos indivíduos que constituem a sociedade.

\section{REFERÊNCIAS}

BONGER, Johanna. Biografia de Vincent Van Gogh por sua cunhada Johanna Antonette Bonger. Trad. William Lagos. Porto Alegre: L\&PM, 2008.

BRASIL. Constituição da República Federativa do Brasil, de 5/10/1988. Disponível em: <http:// www.planalto.gov.br/ccivil_03/constituicao/ ConstituicaoCompilado.htm>. Acesso em: 26 jul. 2012.

EDWARDS, Betty. Exercícios para desenhar com o lado direito do cérebro. Trad. Heitor Pitombo. 1. Reimp. Rio de Janeiro: Ediouro, 2003.

EISNER, Eliot. The Roled Of Discipline-Based Art Education in America's Schools. Getty Education
Institute for the Arts: Los Angeles, USA, 1988.

FREIRE. Paulo. Educação com prática de liberdade. 14a ver. atual. Rio de Janeiro: Paz e Terra, 2011.

GIMENEZ, Marc. 0 que é estética? São Leopoldo: Editora Unisinos, 1999.

IZQUIERDO, Iván. Memória. Porto Alegre: [S.n.], 2011.

UNESCO. Declaração de Salamanca e linha de ação sobre necessidades educativas especiais. Salamanca: Espanha, 1997. Disponível em: <www. direitoshumanos.usp.br/documentos/trata>. Acesso em: 27 jun. 2012.

WALLERSTEIN, Immanuel. As Ciências Sociais no século XXI. Trad. Carina Morgado. New York: Free Press, 1997. Disponível em: <http://www. historiagora.com/dmdocuments/Historia3 ciencias_sociais_seculo_XXI.pdf $>$. Acesso em: $1 \overline{7}$ fev. 2014.

YOUNG, Trevor L. Gestão eficaz de projetos. Trad. Henrique Amar Rêgo Monteiro. São Paulo: Clio, 2007. 